\title{
First Demonstration of the Effects of Remote Per- and Postconditioning on Ischemia and Reperfusion Induced Hepatic Injury
}

\author{
Thiago Barbosa Gonçalves ${ }^{1}$, Vitor Nagai Yamaki*, ${ }^{1}$, João Vitor Baia Coelho ${ }^{1}$, Marcus Vinicius \\ Henriques Brito ${ }^{2}$, and Sandro Percário ${ }^{2}$
}

${ }^{1}$ Experimental Surgery Laboratory, School of Medicine, UEPA, Belem-PA, Brazil

${ }^{2}$ School of Medicine, UEPA, Belem-PA, Brazil

\begin{abstract}
Ischemia and reperfusion is a very frequently phenomenon that is presented in many clinical situations like in liver transplantation as well as in traumatic situation of these organs.One way of minimizing this injury is the remote ischemic perconditioning, described in myocardial ischemia, in which brief nonlethal cycles of ischemia and reperfusion of the arm or leg are applied remotely during index ischemia. Therefore, this current study aims to compare the effects of perconditioning and postconditioning on injury of ischemia and reperfusion in the liver.
\end{abstract}

Keywords: Transplantation, Liver failure, Reperfusion injury.

\section{INTRODUCTION}

One of the most promising treatments for injuries from ischemia and reperfusion is ischemic conditioning that was described first as preconditioning, in 1986 [1], then as postconditioning, in 2003, and recently, as remote ischemic perconditioning, in 2007 [2]. The latter was described only in myocardial, cerebral and kidney ischemia. Studies on its effects on liver ischemia have not been reported so far. Therefore, the goal of this research is to evaluate the effects of this technique in protecting liver ischemia and reperfusion injury induced in rats [3].
Experiments were carried out on 25 Wistar rats, weighing from 270 to $300 \mathrm{~g}$. These were randomly assigned into 5 groups $(n=5)$. After anesthesia, the rats of sham group were subjected only to laparotomy and suture of abdominal wall. The rats of Ischemia and Reperfusion (IR) group were subjected to 1 hour of ischemia, by placing a microsurgical clamp in the hepatic triad that serves the left and median liver lobes, followed by 2 hours of free reperfusion. The rats from postconditioning ischemic group (POST) were subjected to the procedures of the IR group; however, after the period of index ischemia, 6 interspersed cycles of 10 seconds of ischemia and reperfusion were performed (total $=$ 2 minutes), by application and withdrawal of the clamp. The

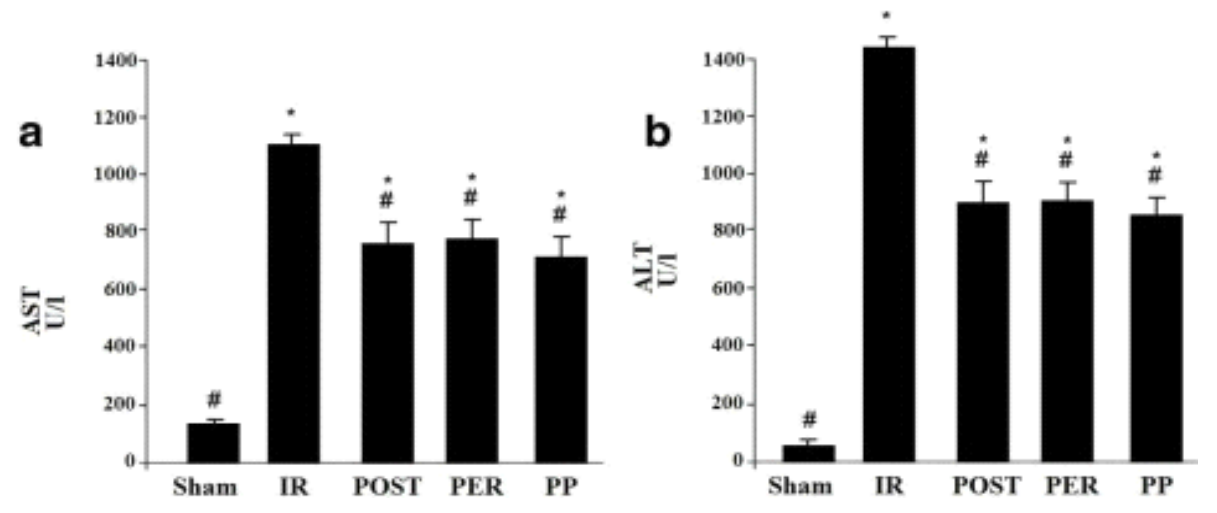

Fig. (1). Liver function indexes in the different groups of the experiment: (a) AST and (b) ALT. *p<0.01 vs. sham group. **p<0.01 vs. IR group. AST: Aspartate transaminase. ALT: Alanine transaminase. IR: Ischemia and reperfusion. POST: Post-conditioning. PER: Perconditioning. PP: Post and Perconditioning.

*Address correspondence to this author at the Rodovia Augusto Motenegro. No 5000. Quadra 7/Lote 8, Brazil; Tel: 55-91-32831876;

Fax: 55-91-32691717; E-mail: vitoryamaki@gmail.com rats from the remote ischemic perconditioning group (PER) were subjected to the procedures of the IR group. After the first 20 minutes of liver ischemia, 4 cycles of 5 minutes of remote ischemic perconditioning were performed (total $=40$ minutes), by application and withdrawal (ischemia and 
reperfusion) of a tourniquet on the animal's left posterior limb. The rats from the ischemic post and perconditioning groups (PP) were subjected, cumulatively, to procedures of PER and POST groups. At the end of reperfusion, a sample of blood was collected and aspartate transaminase (AST) and alanine transaminase (ALT) were measured.

Groups PER (AST: $777.6 \pm 3.25 \%$ / ALT: $875.4 \pm$ $2.08 \%$ ) and POS (AST: $771.2 \pm 3.56 \% /$ ALT: $873 \pm 2.95 \%$ ) were effective in the treatment of injuries from ischemia and reperfusion, showing an improvement in liver function. When the two techniques were simultaneously applied, in the PP group (AST: $753.4 \pm 3.16 \%$ / ALT: $843 \pm 4.75 \%$ ) the results were even better in absolute numbers. When groups PER, POST and PP were analyzed statistically among themselves by ANOVA test followed by Tukey test, there was no statistical relevance $(\mathrm{p}>0.05)$. However, when sham groups were compared (AST: $144 \pm 2.46 \%$ / ALT: $63.4 \pm$ 6.93\%) and IR (AST: $1104.4 \pm 1.54 \%$ / ALT: $1414.6 \pm$ $1.25 \%$ ) with all other groups, there was statistical significance $(\mathrm{p}<0.01)$, showing the success of the groups treated in this study Fig. (1).

Through the analysis of the data, it is possible to note that the remote ischemic perconditioning is an important and promising technique for the prevention of injury of liver ischemia and reperfusion. Its use is even more interesting when taking into account the fact that this is a non-intrusive technique, unlike other ischemic conditionings. Perconditioning may be, within a short time, an important tool for attenuation of reperfusion injury in liver transplantation in humans.

\section{CONFLICTS OF INTEREST}

The authors confirm that this article content has no conflicts of interest.

\section{ACKNOWLEDGEMENTS}

None declared.

\section{REFERENCES}

[1] Crisostomo PR, Wairiuko GM, Wang M, Tsai BM, Morrell ED, Meldrum DR. Preconditioning versus postconditioning: mechanisms and therapeutic potentials. J Am Coll Surg 2006; 202: 797 812 .

[2] Schmidt MR, Smerup M, Konstantinov IE, et al. Intermittent peripheral tissue ischemia during coronary ischemia reduces myocardial infarction through a KATPdependent mechanism: First demonstration of remote ischemic perconditioning. Am J Physiol Heart Circ Physiol 2007; 292: H1883.

[3] Kadkhodaee M, Seifi B, Najafi A, Sedaghat Z. First report of the protective effects of remote per- and postconditioning on ischemia/reperfusion-induced renal injury.Transplantation 2011; 92(10): e55. 